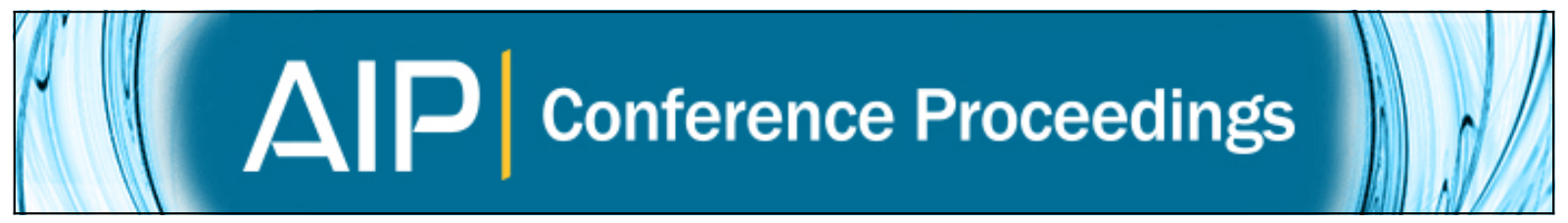

High Protein Structural Flexibility Of A Truncated Hemoglobin From An Antarctic ColdAdapted Bacterium

Barry D. Howes, Daniela Giordano, Leonardo Boechi, Simona Mucciacciaro, Maria Fittipaldi, Darío A. Estrin, Massimo Coletta, Cinzia Verde, and Giulietta Smulevich

Citation: AIP Conference Proceedings 1267, 29 (2010); doi: 10.1063/1.3482523

View online: http://dx.doi.org/10.1063/1.3482523

View Table of Contents: http://scitation.aip.org/content/aip/proceeding/aipcp/1267?ver=pdfcov

Published by the AIP Publishing

Articles you may be interested in

Isotope-enriched protein standards for computational amide I spectroscopy

J. Chem. Phys. 142, 125104 (2015); 10.1063/1.4915271

Communication: Epistructural thermodynamics of soluble proteins

J. Chem. Phys. 136, 091101 (2012); 10.1063/1.3691890

Surface layer protein characterization by small angle x-ray scattering and a fractal mean force concept: From protein structure to nanodisk assemblies

J. Chem. Phys. 133, 175102 (2010); 10.1063/1.3489682

Under-wrapped soluble proteins as signals triggering membrane morphology

J. Chem. Phys. 119, 6911 (2003); 10.1063/1.1605734

Polarized light scattering from sickle hemoglobin polymers

J. Chem. Phys. 107, 1625 (1997); 10.1063/1.474513 


\title{
High Protein Structural Flexibility Of A Truncated Hemoglobin From An Antarctic Cold-Adapted Bacterium.
}

\author{
Barry D. Howes ${ }^{\mathrm{a}}$ Daniela Giordano ${ }^{\mathrm{b}}$, Leonardo Boechi ${ }^{\mathrm{c}}$, Simona \\ Mucciacciaro $^{\mathrm{a}}$, Maria Fittipaldi ${ }^{\mathrm{a}}$, Darío A. Estrin ${ }^{\mathrm{c}}$, Massimo Coletta ${ }^{\mathrm{d}}$, \\ Cinzia Verde ${ }^{\mathrm{b}}$, and Giulietta Smulevich ${ }^{\mathrm{a}}$ \\ ${ }^{a}$ Dipartimento di Chimica, Università di Firenze Via della Lastruccia 3, I-50019 Sesto Fiorentino (Fi), \\ Italy. \\ ${ }^{b}$ Institute of Protein Biochemistry, CNR, Via Pietro Castellino 111, I-80131 Naples, Italy \\ ${ }^{c}$ Departemento de Química Inorgánica, Analítica y Química Física/INQUIMAE-CONICET, Facultad de \\ Ciencias Exactas y Naturales, Universidad de Buenos Aires, Ciudad Universitaria, Pabellón II, Buenos \\ Aires (C1428EHA), Argentina \\ ${ }^{d}$ Dipartimento di Medicina Sperimentale e Scienze Biochimiche, Università di Roma Tor Vergata, Via \\ Montpellier 1, I-00133 Roma, Italy.
}

Although many cold-adapted marine species have been studied, we still have limited knowledge about molecular adaptations at low temperatures. The ability of cold-adapted organisms to survive at permanently low temperatures implies that to perform their physiological functions at adequate rates in freezing habitats, they have overcome constraints imposed by the cold environment through biochemical and physiological adaptations.

In the present study, we present the first detailed characterization of a cold-adapted bacterial $\mathrm{Hb}$. The monomeric hemoglobin $(\mathrm{Hb})$ from the cold-adapted bacterium Pseudoalteromonas haloplanktis have been cloned and over-expressed [1]. The fairly low redox potential suggests that the physiologically relevant form is $\mathrm{Fe}$ (III). Therefore, the protein in its ferric state $(P h-2 / 2 \mathrm{HbO})$ has been characterized by spectroscopic (RR, UV-Vis, and EPR), kinetic measurements and different computer simulation approaches. The results indicate that this protein belongs to Group II (HbO) of the truncated $\mathrm{Hbs}$ family. In particular, sequence alignment of $P h-2 / 2 \mathrm{HbO}$ with other $2 / 2 \mathrm{Hbs}$, indicates that the conserved residues HisF8, TyrB10, TrpG8, TyrCD1 are in the typical positions for Group II Hbs [2,3]. On the proximal side, HisF8 is coordinated to the heme iron, as confirmed by the $v(\mathrm{Fe}-\mathrm{Im})$ stretching mode at 223 $\mathrm{cm}^{-1}$ in the RR spectrum of the deoxy form. The heme distal pocket is characterized by the presence of a Trp (G8 position) and two tyrosyl residues (TyrCD1 and TyrB10).

The present study strongly indicates that the protein has unique features in the ferric state among Group II of $2 / 2 \mathrm{Hbs}$. In fact, unlike other bacterial $\mathrm{Hbs}$, at neutral $\mathrm{pH}$ $\mathrm{Fe}$ (III) $P h-2 / 2 \mathrm{HbO}$ is characterized by one hexa-coordinated HS form (corresponding to that displaying a water molecule coordinated to the heme) and two (by RR) (Figure 1), or three (by EPR) hexa-coordinated LS forms. While one LS form should correspond to a deprotonated Tyr, the other two 6cLS forms are suggested to

\footnotetext{
CP1267, XXII International Conference on Raman Spectroscopy

edited by P. M. Champion and L. D. Ziegler

(C) 2010 American Institute of Physics 978-0-7354-0818-0/10/\$30.00
} 
correspond to either TyrCD1- $\mathrm{O}^{-}$or $\mathrm{TyrB} 10-\mathrm{O}^{-}$, coordinated to the heme $\mathrm{Fe}(\mathrm{III})$ atom and distinguished by different $\mathrm{H}$-bonding properties for each heme bound Tyr. The MD simulations indicate that coordinated TyrCD1 is stabilized by TrpG8 and coordinated TyrB10 by both TrpG8 and TyrCD1. The lower redox potential of $P h$ $2 / 2 \mathrm{HbO}$ at $\mathrm{pH} 7.0$ (i.e., $-80 \mathrm{mV}$ vs SHE), compared to that of horse heart $\mathrm{Mb}$ and human $\mathrm{Hb}(+50 \mathrm{mV}$ and $+135 \mathrm{mV}$, respectively), indeed agrees with the presence of Tyr as axial ligand. Moreover, at least one Tyr coordinated to a heme iron has been identified by RR experiments upon excitation in the tyrosinate-Fe(III) CT band (near $500 \mathrm{~nm}$ ). The spectra taken with the $514.5 \mathrm{~nm}$ excitation wavelength clearly show the enhancement of two polarized bands at 598 and $1509 \mathrm{~cm}^{-1}$. These bands are assigned to the $\mathrm{v}\left(\mathrm{Fe}-\mathrm{O}_{\mathrm{Tyr}}\right)$ and $v_{\mathrm{Tyr}}(\mathrm{C}=\mathrm{C})$ tyrosinate modes, respectively.

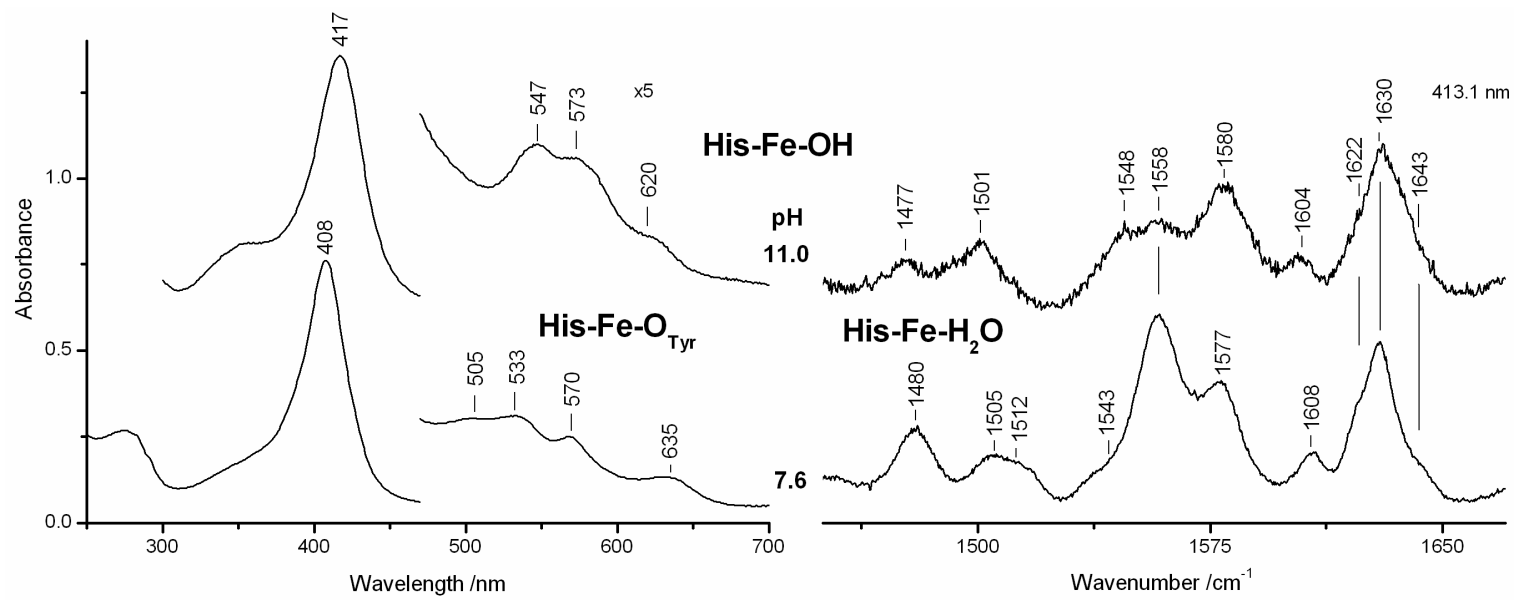

FIGURE 1. UV-Vis (left) and RR (right) spectra of ferric $P h-2 / 2 \mathrm{HbO}$ at different $\mathrm{pH}$ values. At alkaline $\mathrm{pH}$ a new form is observed which has been assigned to be a His-Fe-OH heme complex.

This is the first example in which both TyrCD1 and TyrB10 are proposed to be the residues alternatively involved in heme hexa-coordination by endogenous ligands. The ensemble of results indicates high protein structural flexibility, probably linked to the peculiarity of the cold environment which requires the maintenance of protein flexibility for supporting the cellular functioning.

\section{ACKNOWLEDGMENTS}

This work is financially supported by grants from the Italian Ministero dell'Istruzione, dell'Università e della Ricerca (MIUR) (PRIN 2007SFZXZ7, "Structure, function and evolution of heme proteins from Arctic and Antarctic marine organisms: cold adaptation mechanisms and acquisition of new functions").

\section{REFERENCES}

1. D. Giordano, E. Parrilli, A. Dettaï, R. Russo, G. Barbiero, G. Marino, G. Lecointre, G. di Prisco, M. L. Tutino, C. Verde, Gene 398, 69-77 (2007).

2. J. B. Wittenberg, M. Bolognesi, B. A. Wittenberg, M. Guertin, J. Biol. Chem. 277, 871-874 (2002).

3. D. A. Vuletich, J. T. Lecomte, J. Mol. Evol. 62, 196-210 (2006). 